\title{
Carcinoma of the breast associated with polyethylene strip augmentation
}

\author{
J.P. Roberts and I. Taylor
}

University Surgical Unit, Southampton General Hospital, Tremona Road, Southampton SO1 6HU, UK.

\begin{abstract}
Summary: A case of adenocarcinoma of breast associated with polyethylene prosthesis is presented. The problems with diagnosis and relationship between prosthetic implants and breast carcinoma are discussed.
\end{abstract}

\section{Introduction}

Breast augmentation using a variety of substances has now been available for over 30 years. Direct association of augmentation and subsequent development of carcinoma has yet to be substantiated. The presence of augmentation may hamper diagnosis of malignancy in the remaining breast tissue by masking clinical and radiological signs. We present a case illustrating this problem.

\section{Case report}

A 58 year old woman presented with nodularity and discomfort in the right axillary tail having undergone bilateral breast augmentation at the age of 25 years. Prior to surgery she had successfully breast fed two offspring. There was no family history of breast disease. Examination revealed a fullness in the right axillary tail which was difficult to assess due to the presence of the prosthesis. A mammogram was performed, which was difficult to evaluate due to the prosthesis but no focal lesion was seen. Sonomammogram performed at the same time detected two small nodules lateral to the nipple but these were considered benign after their appearance remained unchanged on repeat examination 4 months later.

The patient was lost to follow-up, only to return 9 months after initial presentation with further discomfort and a distinct lump in the right breast. The lump was more prominent on this occasion and showed obvious puckering of the overlying skin. Fine needle aspiration cytology of the lesion demonstrated the presence of malignant cells and a

Correspondence: Professor I. Taylor M.D., Ch.M., F.R.C.S.

Accepted: 21 November 1989 mastectomy with axillary clearance was subsequently performed.

At operation the tumour was seen to be arising adjacent to a fibrous capsule which surrounded strips of brown discoloured material (Figure 1) and extended through the axillary tail.

Histological examination of the lesion confirmed a ductal carcinoma infiltrating through a fibrous capsule and intermingling with the foreign material. Axillary lymph nodes were involved with tumour. Electron microprobe analysis showed the strips to be hydrocarbon rather than silicone based.

\section{Discussion}

Breast augmentation using polyethylene strips was first described before the advent of silicone. ${ }^{1}$ Appearance of the strips in two cases where implants were removed, up to 11 years postoperatively (for cosmetic reasons) show appearances identical to those in our case. ${ }^{1}$

Histologically the strips become surrounded by a capsule of fibrous tissue, with usually little tissue reaction to the polyethylene.

There have been sporadic case reports of malignancy arising after breast augmentation with polyvinyl alcohol (Ivalon), polyurethane (Etheron) and silicone. ${ }^{2,3}$ In most of these reports the carcinoma arose within a few years of insertion, making a causal relationship unlikely. There are few reports of malignancy arising many years after implantation, which would be a more likely latent period for the development of malignancy given the low degree of tissue reaction to the implant. Only prolonged follow-up will elucidate whether there is an association between an implant material and the incidence of breast carcinoma.

Mammography is not a reliable method of 


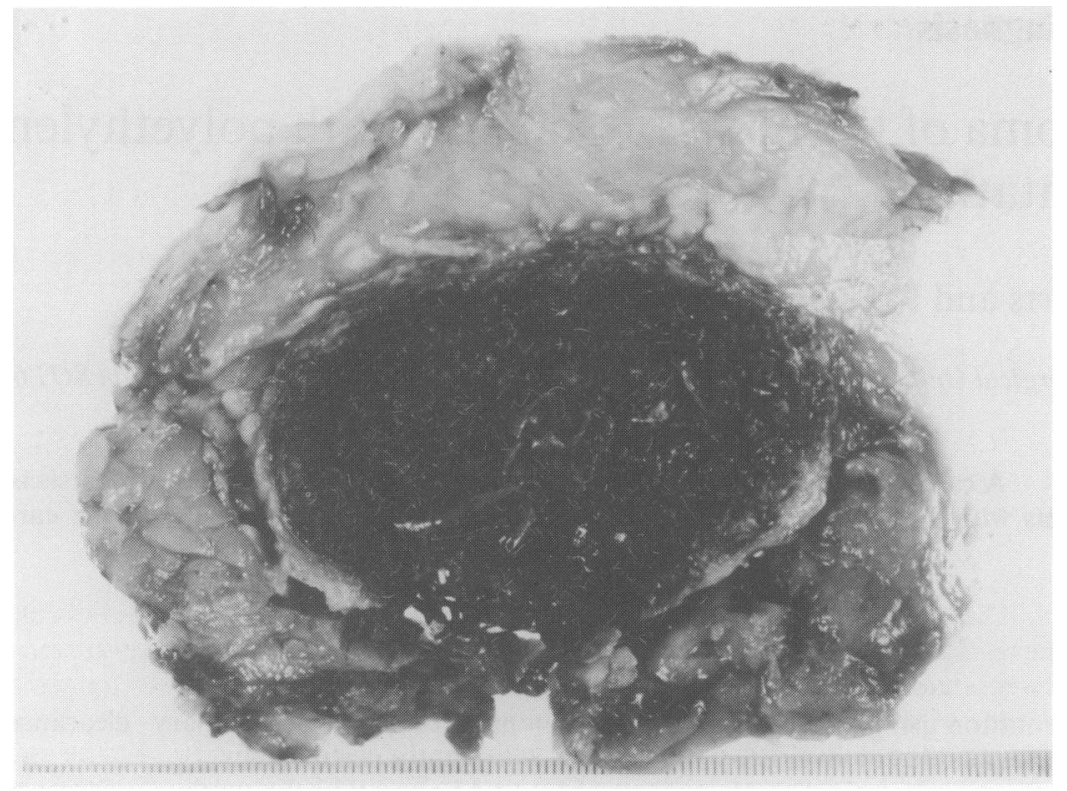

screening for carcinoma in the implanted breast. ${ }^{4}$ As well as the prosthesis obscuring breast tissue, it compresses tissue and the resulting density can mask the presence of small tumours. Mammography is also technically more difficult in the augmented breast. ${ }^{5}$

\section{References}

1. Smahel, J., Schneider, K. \& Donski, P. Bizarre implants for augmentation mammaplasty: long term human reaction to polyethylene strips. Br J Plast Surg 1977, 30: 287-290.

2. Hoopes, J.E., Edgerton, M.T. \& Shelley, W. Organic synthetics for augmentation mammaplasty: their relation to breast cancer. Plast Reconstr Surg 1967, 39: 263-270.

3. Gottlieb, V., Muench, A.G., Rich, J.D. \& Pagadala, S. Carcinoma in augmented breasts. Ann Plast Surg 1984, 12: 67-69.
Regular physical examination and cytologicad $\overrightarrow{0}$ examination or biopsy of any abnormal areas rather than reliance on mammography, is probabt the most useful means of detecting early breas carcinoma in the augmented breast.

4. Hayes, H., Vandergrift, J. \& Diner, W.C. Mammography and breast implants. Plast Reconstr Surg 1988, 82: 1-6.

5. Sadowsky, N.L. Discussion: mammography and breast implants. Plast Reconstr Surg 1988, 82: 7-8. 